\title{
Direct and Reflex Effects of Nitroglycerin on Coronary and Left Ventricular Dynamics in Conscious Dogs
}

\author{
Stephen F. Vatner, Charles B. Higgins, Ronald W. Millard, and \\ Dean FrankLin \\ From the Departments of Medicine, Peter Bent Brigham Hospital, Boston, \\ Massachusetts 02115 and University of California, San Diego, School of \\ Medicine, and Scripps Clinic and Research Foundation, \\ La Jolla, California 92037
}

A B S TRACT The effects of intravenous and sublingual glyceryl trinitrate (nitroglycerin), $40 \mu \mathrm{g} / \mathrm{kg}$, were studied on coronary blood flow and resistance, left ventricular (LV) pressures (P) and diameters (D), rate of change of pressure $(\mathrm{dP} / \mathrm{dt}),(\mathrm{dP} / \mathrm{dt}) / \mathrm{P}$, and on the velocity $(\mathrm{V})$ of myocardial fiber shortening in conscious dogs. Nitroglycerin i.v. caused substantial coronary vasodilatation prior to any changes in systemic hemodynamics. Mean coronary flow increased by a maximum of $47 \mathrm{ml} / \mathrm{min}$ and coronary sinus $\mathrm{P}_{0_{2}}$ rose from 16 to $26 \mathrm{~mm} \mathrm{Hg}$ while pressure and diameter began to fall, and heart rate began to rise. After the maximal fall in mean arterial pressure $(-26 \mathrm{~mm} \mathrm{Hg})$, a secondary peak in coronary flow occurred which was associated with increases in heart rate $(100$ beats $/ \mathrm{min}),(\mathrm{dP} / \mathrm{dt}) / \mathrm{P}$ $(22 \%)$, and isolength $\mathrm{V}(12 \%)$. Beta blockade prevented the reflex increases in contractility but only a part of the reflex tachycardia; the remainder was prevented by cholinergic blockade. Maintaining heart rate constant minimized the decreases in LV D and increases in contractility. When the reflex inotropic and chronotropic effects were prevented by a combination of atrial pacing and beta blockade the early coronary vasodilatation was unaltered, but the later coronary vasodilatation was minimized.

Thus i.v. nitroglycerin in the conscious dog exerts a potent direct coronary vasodilating action and also a secondary coronary vasodilation caused by reflex in-

This work was presented in part at the National Meeting of the Federation of American Societies for Experimental Biology in Atlantic City, N. J., 14 April 1972.

Dr. Higgins is a Surgical Scholar supported by U. S. Public Health Service Grant GM 01559.

Dr. Millard is a Postdoctoral Fellow supported by U. S. Public Health Service Grant HE 40736.

Received for publication 20 April 1972 and in revised form 11 July 1972. creases in contractility and heart rate. The decreases in diameter are largely the result of tachycardia. Sublingual nitroglycerin produced directionally similar, but quantitatively lesser effects on coronary flow and resistance, LV D, LV P, and contractility.

\section{INTRODUCTION}

Existing knowledge regarding the action of nitroglycerin on the normal myocardium and coronary vessels is based primarily on studies either in anesthetized open chest preparations (1-21) or utilizing indirect techniques to assess coronary vasoactivity and myocardial contractility in conscious man (21-26). Since the drug elicits rapid changes in coronary and ventricular dynamics when administered intravenously, it is important to utilize methods which measure coronary blood flow, cardiac dimensions and pressures directly and instantaneously. Furthermore, the hypotensive effects of nitroglycerin elicit reflex increases in heart rate and myocardial contractility which would affect the coronary vessels secondarily and might obscure direct coronary vascular effects. Since anesthesia affects the coronary circulation (27-29), depresses myocardial contractility (30), and alters the normal coronary and myocardial responses to pharmacologic agents, such as cardiac glycosides (29-30), it is essential to describe the normal coronary and myocardial actions of cardiovascular therapeutic agents such as nitroglycerin in the conscious animal in which the complicating influences of anesthesia are absent. This is of particular importance since nitroglycerin reduces arterial pressure and thereby stimulates the baroreceptors, which exert differing effects in the presence and absence of general anesthesia $(28,31)$.

Accordingly, in the present investigation in order to clarify the effects of nitroglycerin on the normal coro- 
nary circulation and myocardium, the drug was administered to healthy, conscious dogs instrumented for direct and continuous measurement of coronary blood flow, arterial and left ventricular $(\mathrm{LV})^{\mathbf{1}}$ pressures $(\mathrm{P})$, left ventricular dimensions, rate of change of pressure $(\mathrm{dP} /$ $\mathrm{dt}$ ), and the velocity (V) of myocardial fiber shortening. In the first part of this study, a large dose of the drug was administered intravenously to provide a description of its pharmacologic properties and its reflex effects. In order to dissect the direct from the reflex effects of nitroglycerin, studies were conducted $(a)$ when heart rate was maintained constant by electrical stimulation of the atria, and $(b)$ after selective and combined beta adrenergic and cholinergic blockades. Finally since the drug is normally administered sublingually, the effects of sublingual were compared with i.v. administration.

\section{METHODS}

15 mongrel dogs, weighing between 23 and $28 \mathrm{~kg}$, were anesthetized with $\mathrm{Na}$ pentobarbital, $30 \mathrm{mg} / \mathrm{kg}$. Through a thoracotomy in the fifth left intercostal space, miniature pressure gauges ${ }^{2}$ were implanted within the left ventricle through a stab wound in the apex; opposing ultrasonic diameter transducers ${ }^{3}$ were sutured to the epicardium of the anterior and posterior walls of the left ventricle and Doppler ultrasonic flow transducers were placed around the left circumflex coronary artery and stimulator electrodes were sutured to the left atrium. Miniature pressure gauges ${ }^{2}$ were implanted in the thoracic aorta (three dogs) and heparin-filled tygon catheters were chronically implanted in the thoracic aorta (11 dogs). In two dogs diameter transducers were implanted on opposing endocardial surfaces of the left ventricle. In two dogs an electromagnetic flow transducer was placed on the left circumflex coronary artery. Heparin-filled tygon catheters were implanted in the coronary sinus during a subsequent right thoracotomy in three dogs anesthetized with $\mathrm{Na}$ pentobarbital, $30 \mathrm{mg} / \mathrm{kg}$.

Both the miniature left ventricular and arterial pressure gauges (32), were calibrated in vivo against a calibrated Statham P23 Db strain gauge manometer.4 At autopsy the position of the ventricular gauges within the ventricular cavity was confirmed. In the eight dogs with previously implanted arterial catheters, arterial pressure was measured with a Statham P23Db strain gauge manometer. Left circumflex coronary blood flow was measured with an ultrasonic Doppler flowmeter $(33,34)$ in 10 dogs. This system which has been described in detail previously, has a reliable zero reference $(33,34)$ and in these experiments electrical zero blood flow was determined repeatedly and was confirmed by calibration when the animal was sacrificed. The relationship between velocity, as measured by the Doppler flowmeter, and volume flow is linear as long as the cross-sectional area of the blood vessel within the transducer remains constant. This linear relationship between velocity and volume flow has been confirmed by

${ }^{1}$ Abbreviations used in this paper: $\mathrm{D}$, diameter; $\mathrm{dD} / \mathrm{dt}$, rate of change of diameter; $\mathrm{dP} / \mathrm{dt}$, rate of change of pressure; $L V$, left ventricular; $P$, pressure; $V$, velocity.

${ }^{2}$ Konigsberg P22, Konigsberg Instruments, Pasadena, Calif.

${ }^{3}$ Construction details available from author.

"Statham Instruments, Inc., Oxnard, Calif. means of timed collections of blood flow (34). At autopsy, it was observed that the vessels were firmly adherent to the flow transducers through a fibrous scar which minimized changes in the cross-sectional area of the vessel within the flow transducers. In two dogs an electromagnetic flowmeter (Statham SP2200) ${ }^{4}$ was used to measure coronary blood flow. Zero flow in these experiments was obtained by inflation of a hydraulic occluder implanted distal to the flow transducer. An improved ultrasonic transit time dimension gauge was used to measure left ventricular diameter; ${ }^{5}$ its principle of operation is similar to that of other ultrasonic gauges described previously $(35,36):$ it measures the transit time of acoustic impulses traveling at the sonic velocity of approximately $1.5 \times 10^{6} \mathrm{~mm} / \mathrm{sec}$ between the 5 or $3 \mathrm{MHz}$ piezoelectric crystals sutured to the left ventricular epicardium or endocardium at opposing sites. It was calibrated by substituting signals of known time duration from a calibrated pulse generator. A voltage proportional to transit time was recorded and calibrated in terms of crystal separation. In this manner a measure of the external or internal diameter of the left ventricle was continuously recorded. At a constant temperature the drift of the instrument is less than $0.15 \mathrm{~mm} / \mathrm{hr}$, and its frequency response is flat to $60 \mathrm{~Hz}$. A Radiometer (Copenhagen) (PHM-72) blood gas analyzer was utilized to measure arterial and coronary sinus $\mathrm{P}_{\mathrm{O}_{2}}$.

The experiments were conducted three weeks to two months postoperatively, when the dogs had recovered from operation and were again vigorous and healthy. While the unsedated dogs were resting quietly, control records of left ventricular pressure, diameter, the time rate of change of diameter $(\mathrm{dD} / \mathrm{dt})$, i.e., the velocity of myocardial shortening, the rate of change of pressure, left circumflex coronary blood flow, arterial pressure, and heart rate were obtained. These variables were continuously recorded during all interventions until all measurements returned to the pre-nitroglycerin control levels. In nine dogs, glyceryl trinitrate (nitroglycerin), $40 \mu \mathrm{g} / \mathrm{kg}$, was administered intravenously in a bolus. This dose consistently resulted in marked and reproducible hemodynamic effects without causing any detectable discomfort to the conscious animal. If the animals showed any awareness of receiving the drug systemically or sublingually, the experiment was discarded. Seven of these dogs were also studied $(a)$ with heart rate controlled by means of electrical stimulation of the atria at the peak frequency attained after a control injection of nitroglycerin, (b) after beta receptor blockade with propranolol, $1.0 \mathrm{mg}$ / $\mathrm{kg}$, (c) after beta receptor blockade and with heart rate controlled at the frequency attained following nitroglycerin after beta receptor blockade, $(d)$ after combined beta receptor blockade and cholinergic blockade with atropine 0.2 $\mathrm{mg} / \mathrm{kg}$, and $(e)$ on a separate day before and after selective cholinergic blockade with atropine $0.2 \mathrm{mg} / \mathrm{kg}$. The adequacy of beta blockade was tested with isoproterenol $1 \mu \mathrm{g} /$ $\mathrm{kg}$. In six dogs nitroglycerin, $40 \mu \mathrm{g} / \mathrm{kg}$, was dissolved in 1 $\mathrm{cm}^{3}$ tap water and placed sublingually both while the dogs were in sinus rhythm and after heart rate was controlled with atrial stimulation at the frequency attained following sublingual nitroglycerin in the control state. This was the smallest dose that consistently caused perceptible changes in systemic and coronary dynamics. The results of two responses to nitroglycerin in each state were averaged for each animal and analyzed statistically with standard errors and paired $t$ tests (37).

${ }^{5}$ Circuit diagrams available from authors. 


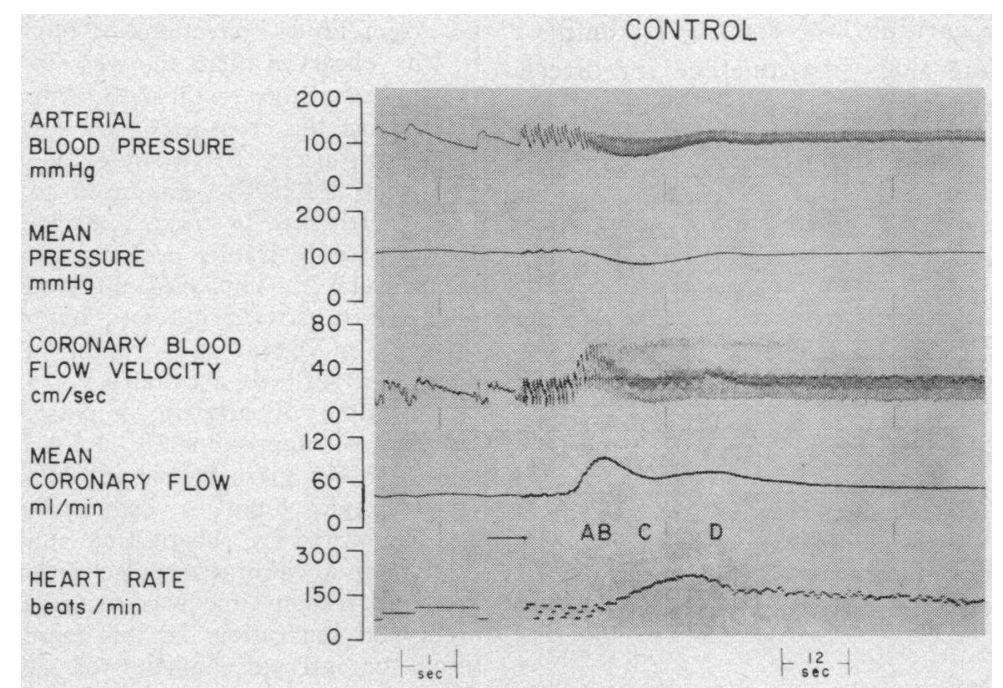

FIGURE 1 The early striking increase in phasic and mean coronary flow that occurs before alterations in arterial pressure or heart rate is shown. $A$ is the point of coronary dilatation before systemic effects. $B$ is the maximal increase in coronary flow. $C$ is the maximal hypotensive effects. $D$ is the secondary rise in coronary flow which occurred at the point of maximal inotropic effect.

Data were recorded on a multichannel tape recorder and played back on a direct writing oscillograph at a paper speed of $100 \mathrm{~mm} / \mathrm{sec}$. A cardiotachometer, triggered by the

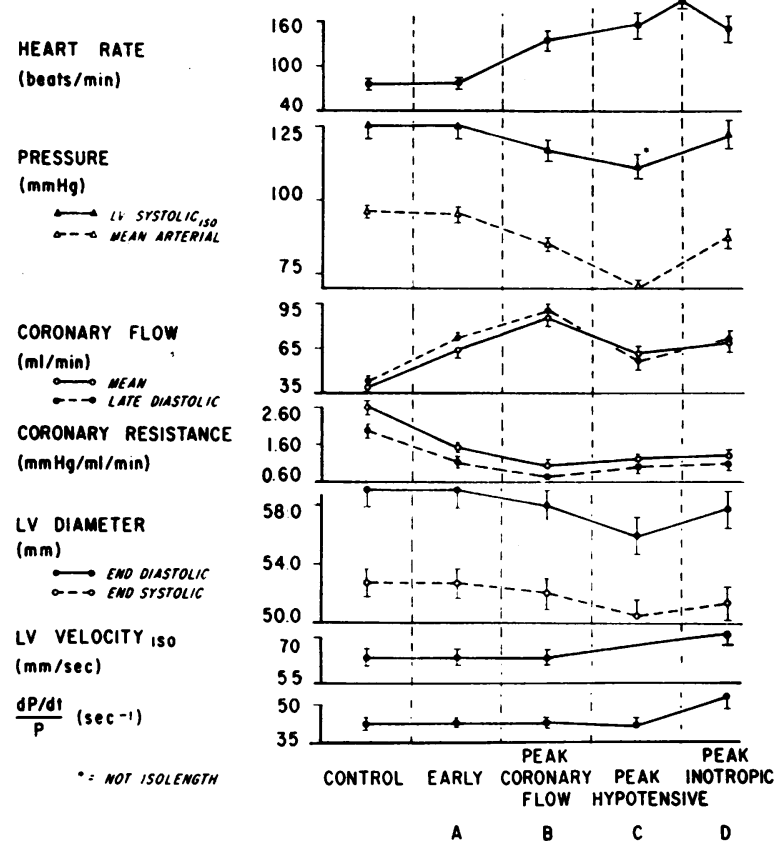

FIgure 2 The normal response to i.v. nitroglycerin, 40 $\mu \mathrm{g} / \mathrm{kg}$, is shown for heart rate, isolength LV systolic pressure and mean arterial pressure, mean and late diastolic coronary flow and resistance, end diastolic and end systolic diameters, $\mathrm{LV}$ isolength velocity and $(\mathrm{dP} / \mathrm{dt}) / \mathrm{P}$. The control values (1st panel) are compared with points $A$ through D. signal from the pressure pulse, provided instantaneous and continuous records of heart rate. Electronic RC filters having $2 \mathrm{sec}$ time constants were used to derive mean arterial blood pressure and mean left circumflex coronary blood flow. Mean and late diastolic coronary resistances were calculated as the quotients of mean and late diastolic arterial pressures and coronary blood flows respectively. Continuous records of $\mathrm{dP} / \mathrm{dt}$ and $\mathrm{dD} / \mathrm{dt}$ were derived from the left ventricular pressure and diameter signals, using Philbrick operational amplifiers connected as differentiators. A triangular wave signal with known slope (rate-of-change) was substituted for pressure and diameter signals to calibrate directly the $\mathrm{dP} / \mathrm{dt}$ and $\mathrm{dD} / \mathrm{dt}$ channels.

The effects of nitroglycerin on myocardial force-velocity relations were assessed by determining their effects on the velocity of shortening and intraventricular pressure at an identical ventricular diameter (isolength point), by the technique described in detail previously $(30,31,38)$. All isolength points were obtained during the first one-third of ejection. In addition, the effects on peak $\mathrm{dP} / \mathrm{dt}$ and the quotient of $\mathrm{dP} / \mathrm{dt}$ and developed pressure (left ventricular isovolumic minus end diastolic pressure) i.e., $(\mathrm{dP} / \mathrm{dt}) / \mathrm{P}$, were examined. The same level of pressure which occurred during isometric contraction, before and after each intervention, was used for this calculation and $d P / d t$ and $P$ were determined at that level of pressure. This technique for evaluating the myocardial contractile state has been described in detail previously $(30,31,39,40)$.

\section{RESULTS}

Four points were chosen to analyze data after i.v. nitroglycerin, $40 \mu \mathrm{g} / \mathrm{kg}$ (Fig. 1). The first point (A) was the instant at which arterial pressure began to fall. The second (B) was the instant of the first peak in coronary flow. The third (C) was the instant of the minimum level arterial pressure attained. The fourth (D) was at 
the point of maximal reflex effects on myocardial contractility. Point A occurred $7 \pm 1$ (SE) sec, B occurred at $9 \pm 1 \mathrm{sec}, C$ at $18 \pm 2 \mathrm{sec}$, and $D$ at $29 \pm 3 \mathrm{sec}$ after i.v. injection of nitroglycerin.

\section{Effects of i.v. nitroglycerin, $40 \mu \mathrm{g} / \mathrm{kg}$ ( eight dogs )}

Heart rate. After the decline in arterial pressure, heart rate rose from $75 \pm 4$ to a maximum of $175 \pm 8$ beats $/ \mathrm{min}$. The maximum increase in heart rate occurred after the peak hypotensive effects, $\mathrm{C}$, but before the peak inotropic effects, D, of nitroglycerin (Fig. 2).

Pressure. Mean arterial pressure decreased following nitroglycerin, falling to a minimum level of $70 \pm 3 \mathrm{~mm} \mathrm{Hg}$ at point $\mathrm{C}$ from a control of $96 \pm 2 \mathrm{~mm} \mathrm{Hg}$ (Fig. 2) and returned to control by $159 \pm 12 \mathrm{sec}$ after i.v. injection of nitroglycerin. Peak LV systolic pressure followed a similar pattern, decreasing from $130 \pm 5$ to $111 \pm 4 \mathrm{~mm} \mathrm{Hg}$. $\mathrm{LV}$ end diastolic pressure fell from $8 \pm 1$ to $2 \pm 1 \mathrm{~mm} \mathrm{Hg}$, gradually returning to control by 3 min after the administration of nitroglycerin, which was slightly later than the return of systolic LV P and mean arterial pressure.

Coronary bcd. Nitroglycerin increased mean left circumflex coronary flow before any detectable changes in arterial or ventricular pressures, heart rate, left ventricular dimensions, or contractility (Fig. 3). At this point, A, mean coronary flow had risen from $38 \pm 2$ to $63 \pm 2 \mathrm{ml} / \mathrm{min}$ and mean coronary resistance had decreased from $2.56 \pm 0.09$ to $1.52 \pm 0.05 \mathrm{~mm} \mathrm{Hg} / \mathrm{ml}$ per min. Mean coronary flow reached a maximum of $85 \pm 3 \mathrm{ml} /$ min, while mean coronary resistance fell to a minimum of $1.02 \pm 0.04 \mathrm{~mm} \mathrm{Hg} / \mathrm{ml}$ per min (B). Mean coronary flow declined slightly with maximal decrease in arterial pressure (C) and then reached a secondary peak of $69 \pm 6 \mathrm{ml} / \mathrm{min}$ associated with the reflex changes in heart rate and contractility (D) and then gradually returned to control. Although the increases in late diastolic coronary flow and decreases in late diastolic resistance were slightly less when pressure fell (Fig. 2), even during the peak hypotensive effects $(C)$, late diastolic flow exceeded control and late diastolic resistance was below control. At this point there was an associated increase in the systolic fraction of coronary flow, $42 \pm 5 \%$, as compared with the fraction existing before drug administration, $23 \pm 4 \%$. When flow was measured with the directional electromagnetic flowmeter, a small fraction of systolic flow did reverse during the peak hypotensive response. This fraction was never more than $5 \%$ of total left circumflex coronary flow. Thus, the mean flow that was recorded with the Doppler flowmeter during the peak hypotensive effects may have actually been overestimated by a maximum of $10 \%$. However, this reservation does

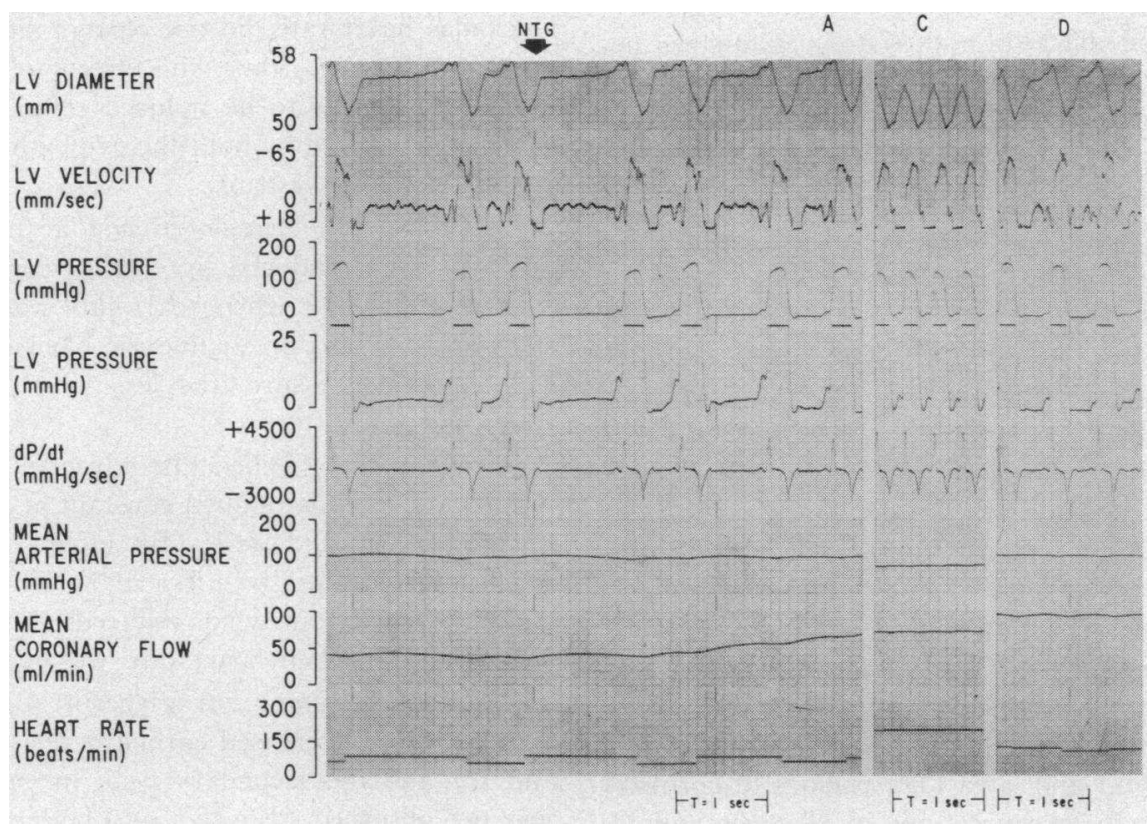

FIgURE 3 A typical response to i.v. nitroglycerin (NTG), $40 \mu \mathrm{g} / \mathrm{kg}$ in a conscious dog. The phasic wave forms for LV diameter, LV velocity, LV systolic and diastolic pressures, $\mathrm{dP} / \mathrm{dt}$, are shown simultaneously with mean arterial pressure, mean coronary flow, and heart rate. The control and early rise in coronary flow (A) which occurred before systemic changes (left panel) can be compared with peak hypotensive effects (C) and the peak inotropic effects (D). 


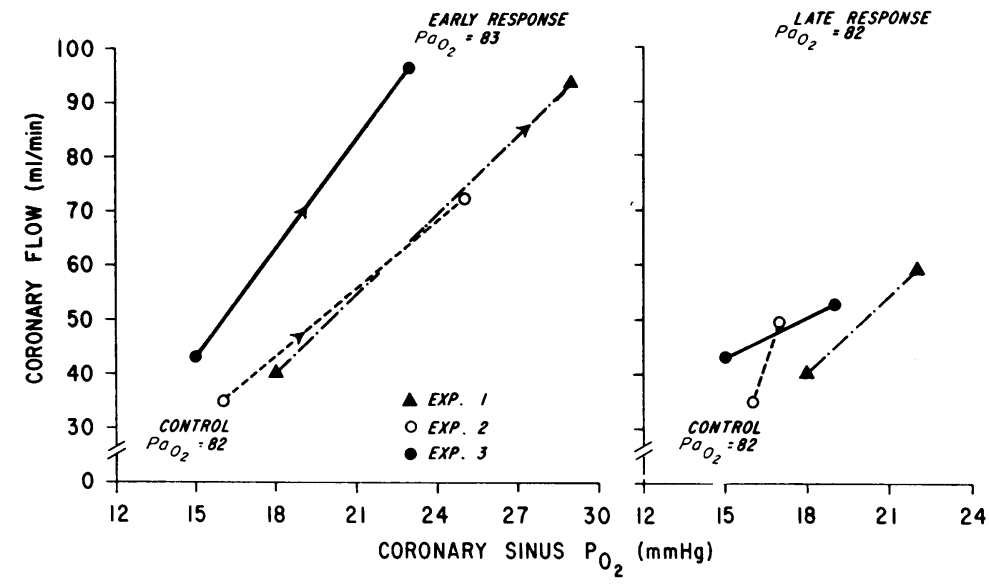

FIGURE 4 The average of three determinations of coronary sinus oxygen values for each of three dogs are plotted against their coronary flow responses. The early response to i.v. nitroglycerin (left panel) can be compared with the later effects (right panel). The simultaneous average values for arterial $\mathrm{P}_{\mathrm{O}_{2}}$ are noted.

not apply to the early and peak coronary effects nor does it apply to measurements of late diastolic coronary flow or calculations of late diastolic coronary resistance.

Left ventricular dimensions. Left ventricular diameter began to decrease when pressure fell and heart rate rose (B) ; during peak tachycardia and minimal pressure (C), end diastolic diameter was $3.1 \pm 0.2 \mathrm{~mm}$ below a control of $59.1 \pm 1.1 \mathrm{~mm}$. End systolic diameter fell by a slightly lesser amount $2.8 \pm 0.2 \mathrm{~mm}$ from a control of $52.8 \pm 1.0$ $\mathrm{mm}$ (Fig. 2). End diastolic and systolic diameters began to return to control when pressure increased, and were still slightly reduced when pressure had returned to control. In the one dog in which it was measured internal end diastolic and systolic diameters decreased by 4.3 and $3.3 \mathrm{~mm}$, respectively, from control values of 38.4 and $28.5 \mathrm{~mm}$, respectively.

Myocardial contractile state. Although peak $\mathrm{dP} / \mathrm{dt}$ fell slightly with pressure, $(\mathrm{dP} / \mathrm{dt}) / \mathrm{P} \operatorname{did}$ not show a significant change in the early responses, (A-C) but increased at point $\mathrm{D}$ by $22 \pm 2 \%$ above a control of $43 \pm 2 \mathrm{sec}^{-1}$ (Fig. 2). At the time of maximal increase in $(\mathrm{dP} / \mathrm{dt}) / \mathrm{P}$, isolength velocity had also increased, by $17 \pm 2 \%$ from a control of $62 \pm 4 \mathrm{~mm} / \mathrm{sec}$. At this point isolength systolic left ventricular pressure was slightly reduced, $122 \pm$ $4 \mathrm{~mm} / \mathrm{Hg}$ as compared with a control of $125 \pm 4 \mathrm{~mm} / \mathrm{Hg}$.

Arterial and coronary venous oxygen. In three dogs simultaneous arterial and coronary sinus oxygen determinations were made before drug administration, and during the early (B) and later (D) periods of coronary vasodilatation. In all determinations in all three animals nitroglycerin did not alter arterial oxygen tension but increased coronary sinus $\mathrm{P}_{o_{2}}$ from $16 \pm 1$ to $26 \pm 2 \mathrm{~mm} \mathrm{Hg}$ during the early response, i.e., at point $\mathrm{B}$, and then coronary sinus $\mathrm{P}_{o_{2}}$ declined to $19 \pm 2 \mathrm{~mm} \mathrm{Hg}$, at point $\mathrm{D}$, during the later period of coronary vasodilatation (Fig. 4).
Effects of i.v. nitroglycerin, $40 \mu \mathrm{g} / \mathrm{kg}$, after reflex effects prevented

Heart rate. Beta receptor blockade did not significantly affect resting heart rate, but following nitroglycerin, the rate increased from $75 \pm 3$ to only $125 \pm 5$ beats/ min. Cholinergic blockade increased heart rate to $173 \pm 11$ beats/min and nitroglycerin increased it further to $209 \pm 8$ beats/min. After combined beta and cholinergic blockades heart rate did not change significantly following nitroglycerin. Thus, the effects of nitroglycerin on heart rate appear to be induced reflexly and the tachycardia is mediated by both the sympathetic and parasympathetic nervous systems.

Pressure. The changes in systolic LV $\mathrm{P}$ or mean arterial pressure induced by nitroglycerin were not substantially different when heart rate was maintained constant or after beta or cholinergic blockade, but the fall in end diastolic pressure was less when the rise in heart rate was reduced.

Coronary bed. When nitroglycerin was administered with heart rate maintained constant at $175 \pm 8$ beats $/$ min, the early (A) and peak (B) effects on coronary flow were not substantially different but the later effects (C and D) were somewhat reduced. After beta receptor blockade, and when heart rate was maintained constant at $125 \pm 5$ beats/min, nitroglycerin still increased coronary flow and decreased coronary resistance initially (A and $B$ ), but the secondary peak in coronary flow (D) was not observed (Fig. 5), and both coronary flow and resistance returned to control earlier. Coronary resistance returned to control by $94 \pm 8 \mathrm{sec}$ as compared with $156 \pm 17 \mathrm{sec}$ in the control state (Fig. 6). After combined beta receptor and cholinergic blockades coronary flow and resistance showed similar changes to nitro- 


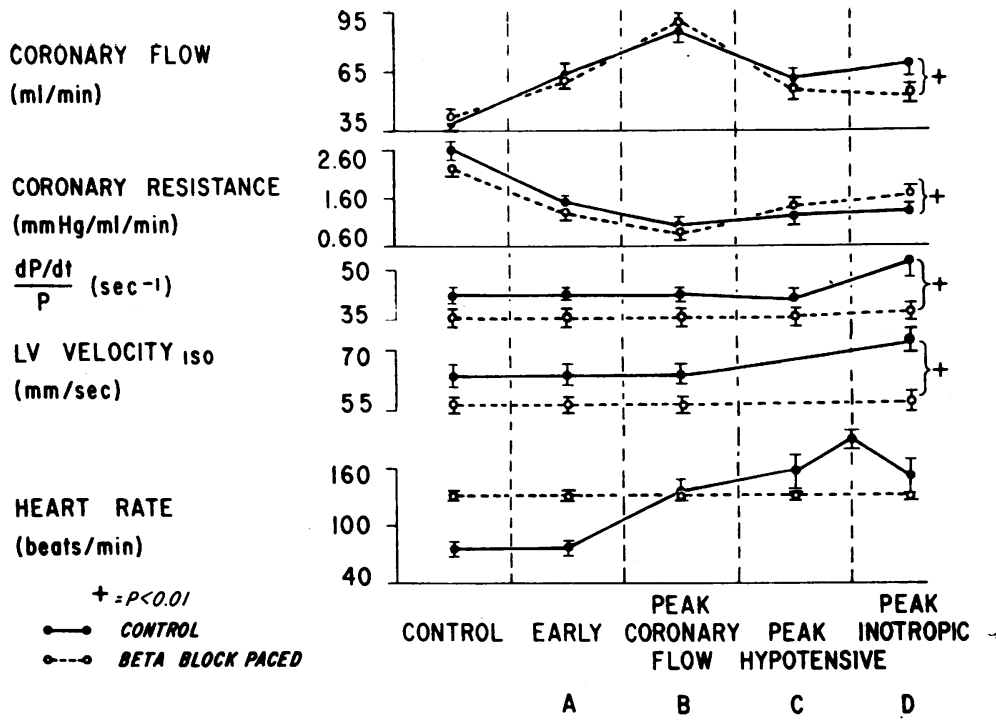

Figure 5 The normal responses (solid lines) and those following beta blockade and heart rate held constant with atrial pacing (broken lines) are compared following i.v. nitroglycerin, $40 \mu \mathrm{g} / \mathrm{kg}$, on mean coronary flow and resistance, $(\mathrm{dP} / \mathrm{dt}) / \mathrm{P}$, isolength velocity, and heart rate. Note that preventing reflex effects does not substantially affect the early or peak coronary effects but modifies the later coronary response.

glycerin as occurred following beta blockade with heart rate constant.

Thus, nitroglycerin causes two phases of coronary vasodilatation the first is primarily direct, while the second is primarily due to reflex increases in heart rate and myocardial contractility (Fig. 6).

Left ventricular dimensions. When heart rate was held constant either in the control state or after beta blockade, the reduction in external or internal diameters with nitroglycerin was substantially attenuated (Fig. 7). Thus, the reduction in ventricular size that occurred with nitroglycerin was due mainly to the tachycardia that occurred and to a lesser extent to the peripheral effects.

Myocardial contractile state. When heart rate was maintained constant but prior to autonomic blockade the later increases (D) in ( $\mathrm{dP} / \mathrm{dt}) / \mathrm{P}$ was only $17 \pm 3 \%$ from a control of $42 \pm 3 \mathrm{sec}^{-1}$ (Fig. 7). This was slightly but significantly less $(P<0.01)$ than the response in spontaneous rhythm $(22 \pm 2 \%)$. After beta blockade and with heart rate constant, $(\mathrm{dP} / \mathrm{dt}) / \mathrm{P}$ did not increase after the decline in pressure with nitroglycerin. When heart rate was maintained constant, although isolength

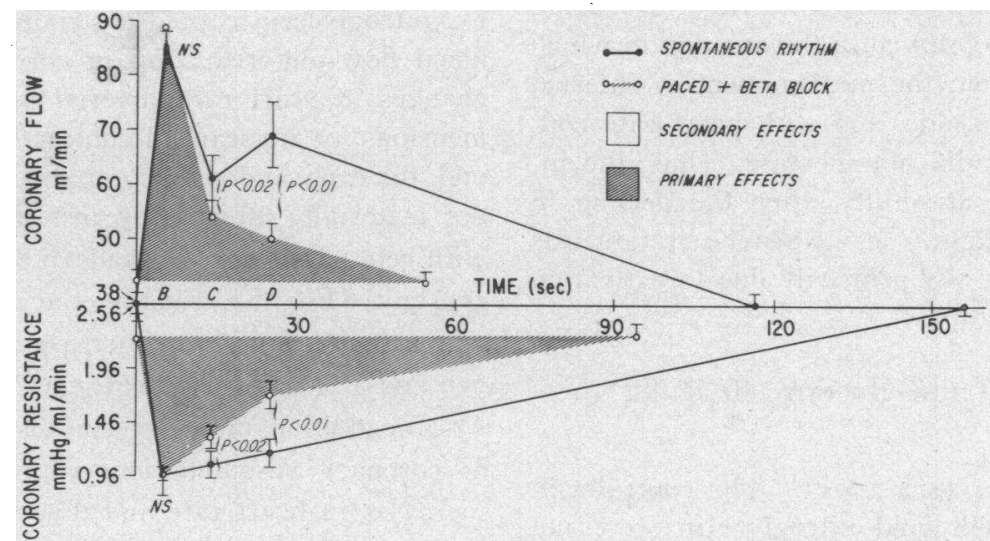

FIGURE 6 The relative contributions of the direct and secondary effects of intravenous nitroglycerin, $40 \mu \mathrm{g} / \mathrm{kg}$, to the responses of coronary flow (top) and coronary resistance (bottom) are shown. The smaller shaded area represents the direct action of the drug on coronary vessels, while the amount due to secondary effects is shown by the clear areas. 


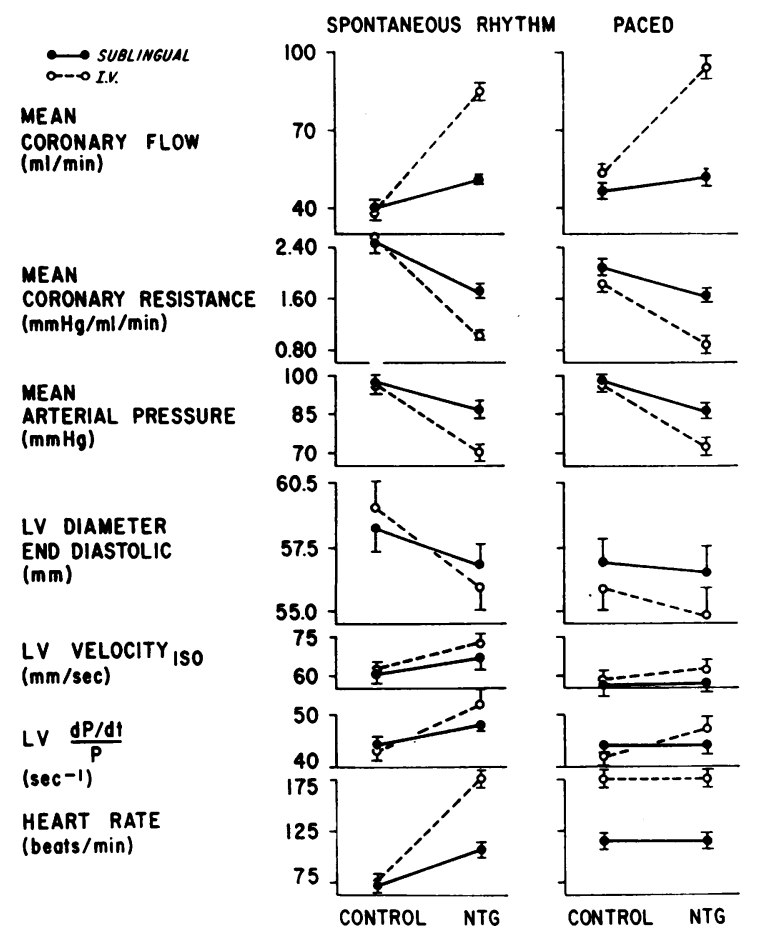

FIGURE 7 Peak responses to nitroglycerin (NTG), 40 $\mu \mathrm{g} / \mathrm{kg}$, are compared for the i.v. (broken lines) and sublingual (solid lines) routes of administration in spontaneous rhythm (left panel) and when heart rate was maintained constant (right panel). There was no significant difference between the control values before nitroglycerin when administered sublingually or intravenously but all the changes following i.v. nitroglycerin were significantly greater $(P$ $<0.01)$.

pressure had decreased by a similar amount, the increase in isolength velocity was only $10 \pm 1 \%$ from a control of $56 \pm 4 \mathrm{~mm} / \mathrm{sec}$, which was less $(P<0.05)$ than occurred when heart rate was allowed to vary $(17 \pm 2 \%)$. A similar response was observed in the one dog in which velocity was derived from the measurement of internal diameter. After beta blockade, and with heart rate constant, isolength velocity did not increase. Thus, the increase in myocardial contractility after the decline in arterial pressure was slightly less when heart rate was maintained constant but was primarily due to activation of myocardial beta receptors.

\section{Effects of sublingual nitroglycerin, $40 \mu \mathrm{g} / \mathrm{kg}$, (Table I)}

Spontaneous rhythm (six dogs). The control values at rest prior to sublingual nitroglycerin were not significantly different from the control values before i.v. nitroglycerin, but the response was different from the i.v. effects in time course and magnitude of effect. Heart rate increased by only $32 \pm 2$ beats $/$ min. Mean arterial pressure gradually declined and fell by a maximum of $10 \pm 1 \mathrm{~mm} \mathrm{Hg}$ at $2 \mathrm{~min}$ and returned to control after $9 \mathrm{~min}$. Left ventricular isolength pressure fell from $120 \pm 2$ to $107 \pm 2 \mathrm{~mm} \mathrm{Hg}$, while end diastolic pressure fell from $8 \pm 1$ to $4 \pm 1 \mathrm{~mm} \mathrm{Hg}$. End diastolic and systolic diameters decreased by $1.4 \pm 0.1$ and $1.3 \pm 0.2 \mathrm{~mm}$, respectively. The reduction in internal dimensions in two dogs with sublingual nitroglycerin were slightly greater (Table I). A slight positive inotropic effect was observed: $(\mathrm{dP} / \mathrm{dt}) / \mathrm{P}$ increased by $9 \pm 1 \% \mathrm{sec}^{-1}$, while isolength velocity increased by $12 \pm 2 \%$. Mean coronary flow rose slightly, by only $10 \pm 1 \mathrm{ml} / \mathrm{min}$, and mean coronary resistance declined by $0.71 \pm 0.6 \mathrm{~mm} \mathrm{Hg} / \mathrm{ml}$ per min. The peak increase in coronary flow and decrease in coronary resistance occurred at the time of maximal reduction in pressures and cardiac dimensions (average $=2$ $\min )$. All these changes with sublingual nitroglycerin were significant (Table I), but were significantly less $(P<0.01)$ than those observed when the drug was administered intravenously (Fig. 7).

Paced (six dogs). When heart rate was maintained constant at $114 \pm 5$ beats $/ \mathrm{min}$, the changes in mean arterial and LV systolic pressures were similar to those occurring when heart rate was allowed to vary spontaneously, but the reductions in both end diastolic $(-0.4 \pm 0.1 \mathrm{~mm})$ and end systolic $(-0.4 \pm 0.1 \mathrm{~mm}) \mathrm{di}-$ ameters were significantly less $(P<0.01)$, and the increases in $(\mathrm{dP} / \mathrm{dt}) / \mathrm{P}$ and isolength velocity were not observed (Fig. 7). The rise in mean coronary flow, $5 \pm 1 \mathrm{ml} / \mathrm{min}$, and the decrease in coronary resistance, $0.43 \pm .05 \mathrm{~mm} \mathrm{Hg} / \mathrm{ml}$ per min, were also less $(P<0.01)$.

\section{DISCUSSION}

In the present investigation nitroglycerin was found to be a potent primary coronary vasodilator in the healthy, conscious dog. The evidence for this is threefold. First, i.v. nitroglycerin caused a striking increase in coronary blood flow and reduction in coronary resistance before changes in heart rate, arterial pressure, ventricular dimensions, or myocardial contractility (Figs. 1,3 ). Second, the early and peak coronary vasodilator effects were not materially affected by preventing the reflex effects with beta adrenergic blockade and maintaining heart rate constant (Fig. 5). Finally, the coronary vasodilatation was associated with an increase in coronary sinus oxygen and a narrowing of coronary $\mathrm{A}-\mathrm{V}_{\mathrm{O}_{2}}$ difference (Fig. 4). In addition nitroglycerin resulted in a later period of coronary vasodilatation, which was associated with increases in heart rate and myocardial contractility and much less of an increase in coronary sinus oxygen. Thus, i.v. nitroglycerin causes two phases of coronary vasodilatation in the conscious dog; the first phase is due to a direct effect on the coronary vessels, while the latter is 
TABLE I

Maximal Effects of Sublingual Nitroglycerin, $40 \mu \mathrm{g} / \mathrm{kg}$

\begin{tabular}{|c|c|c|}
\hline & \multicolumn{2}{|c|}{ Average results } \\
\hline & Control & Nitroglycerin \\
\hline \multicolumn{3}{|l|}{ Heart rate (beats/min) } \\
\hline Spontaneous rhythm & $74 \pm 4$ & $106 \pm 4^{*}$ \\
\hline Paced & $114 \pm 5$ & $114 \pm 5^{*}$ \\
\hline \multicolumn{3}{|l|}{ Arterial pressure $(\mathrm{mm} \mathrm{Hg})$} \\
\hline \multicolumn{3}{|l|}{ Mean/late diastolic } \\
\hline Spontaneous rhythm & $97 \pm 2 / 82 \pm 2$ & $87 \pm 2^{*} / 72 \pm 2^{*}$ \\
\hline Paced & $98 \pm 2 / 86 \pm 1$ & $86 \pm 2 * / 73 \pm 1^{*}$ \\
\hline \multicolumn{3}{|l|}{ Coronary flow $(\mathrm{ml} / \mathrm{min})$} \\
\hline \multicolumn{3}{|l|}{ Mean/late diastolic } \\
\hline Spontaneous rhythm & $40 \pm 2 / 45 \pm 3$ & $51 \pm 2^{*} / 56 \pm 3^{*}$ \\
\hline Paced & $47 \pm 3 / 52 \pm 3$ & $52 \pm 3^{*} / 57 \pm 3^{*}$ \\
\hline \multicolumn{3}{|c|}{ Coronary resistance $(\mathrm{mm} \mathrm{Hg} / \mathrm{ml} \mathrm{per} \mathrm{min})$} \\
\hline \multicolumn{3}{|c|}{ Mean/late diastolic } \\
\hline Spontaneous rhythm & $2.43 \pm 0.14 / 1.85 \pm 0.11$ & $1.72 \pm 0.08^{*} / 1.32 \pm 0.05^{*}$ \\
\hline Paced & $2.10 \pm 0.12 / 1.68 \pm 0.09$ & $1.66 \pm 0.08^{*} / 1.30 \pm 0.06^{*}$ \\
\hline \multicolumn{3}{|c|}{ LV pressure $(m m H g)$} \\
\hline \multicolumn{3}{|c|}{ Peak/isolength/end diastolic } \\
\hline Spontaneous rhythm & $124 \pm 3 / 120 \pm 2 / 8 \pm 1$ & $112 \pm 2^{*} / 107 \pm 2 / 4 \pm 1^{*}$ \\
\hline Paced & $124 \pm 3 / 120 \pm 3 / 5 \pm 1$ & $111 \pm 3^{*} / 108 \pm 2^{*} / 3 \pm 1 \ddagger$ \\
\hline \multicolumn{3}{|l|}{ Peak dP/dt $(m m ~ H g / s e c)$} \\
\hline Spontaneous rhythm & $3630 \pm 160$ & $4070 \pm 180^{*}$ \\
\hline Paced & $3580 \pm 170$ & $3610 \pm 190 \S$ \\
\hline \multicolumn{3}{|l|}{$(\mathrm{dP} / \mathrm{dt}) / \mathrm{P}\left(\sec ^{-1}\right)$} \\
\hline Spontaneous rhythm & $44 \pm 1$ & $48 \pm 1^{*}$ \\
\hline Paced & $44 \pm 1$ & $44 \pm 1 \S$ \\
\hline \multicolumn{3}{|c|}{ LV epicardial diameter $(m m)$} \\
\hline \multicolumn{3}{|l|}{ End diastolic/end systolic } \\
\hline Spontaneous rhythm & $58.2 \pm 0.9 / 51.9 \pm 0.9$ & $56.8 \pm 0.8^{*} / 50.6 \pm 0.8^{*}$ \\
\hline Paced & $56.9 \pm 0.9 / 50.8 \pm 0.9$ & $56.5 \pm 1.0 \ddagger / 50.5 \pm 0.9 \ddagger$ \\
\hline \multicolumn{3}{|l|}{ LV endocardial diameter" } \\
\hline \multicolumn{3}{|l|}{ End diastolic/end systolic } \\
\hline Spontaneous rhythm & $40.4 / 31.8$ & $39.0 / 30.4$ \\
\hline Paced & $39.1 / 30.6$ & $38.5 / 30.2$ \\
\hline \multicolumn{3}{|l|}{$\mathrm{LV}$ velocity $(\mathrm{mm} / \mathrm{sec})$} \\
\hline \multicolumn{3}{|l|}{ Peak/isolength } \\
\hline Spontaneous rhythm & $68 \pm 5 / 61 \pm 4$ & $76 \pm 6 \ddagger / 67 \pm 5 \ddagger$ \\
\hline Paced & $63 \pm 4 / 56 \pm 4$ & $66 \pm 5 / 57 \pm 4 \S$ \\
\hline
\end{tabular}

* Significantly different (paired $t$ test) from control $P<0.01$.

$\ddagger$ Significantly different (paired $t$ test) from control $P<0.05$.

$\$$ Not significantly different (paired $t$ test) from control.

II Two dogs.

metabolic and due to the reflexly induced increases in heart rate and myocardial contractility.

Vyden et al. (8) and Gillis and Melville (9) reported coronary vasodilatation with i.v. nitroglycerin in the open-chest anesthetized dog, but no effect was observed when the drug was given to these animals sublingually. Similarly, Eckenhoff and Hafkenschiel observed little effect due to sublingual nitroglycerin (4). In contrast, in the present study, sublingual nitroglycerin, $40 \mu \mathrm{g} / \mathrm{kg}$, produced directionally similar but quantitatively lesser 
effects on coronary flow, and resistance, arterial and ventricular pressures, ventricular dimensions, myocardial contractility, and heart rate (Fig. 7). Sublingual nitroglycerin in the presence of a constant heart rate was not associated with increases in $(\mathrm{dP} / \mathrm{dt}) / \mathrm{P}$ or isolength velocity but coronary resistance fell slightly $(20 \%)$, indicating that even when administered sublingually at a dose which produced changes in systemic hemodynamics similar to those reported for man $(21-23,41)$, a distinct direct effect on the coronary vessels could be identified. Considering the minor rise in coronary flow and the moderate extent of coronary vasodilatation, it is not surprising that prior studies utilizing indirect techniques $(22,24,42,43)$ or studies in open chest preparations in which the coronary bed may already have been partially dilated by the effects of anesthesia and surgery $(4,8,9)$ could not identify an effect due to sublingual nitroglycerin. If in the present investigation only coronary flow had been measured following sublingual nitroglycerin, when the increases in rate and contractility were prevented by atrial stimulation, it would be concluded that nitroglycerin has a negligible effect on the coronary bed. However, since arterial pressure fell, a significant reduction in coronary resistance occurred, indicating that sublingual nitroglycerin exerts a moderate vasodilating action on the normal coronary bed, even when heart rate and contractility remain constant. Similarly, Rowe et al. (43) and Hollander et al. (44) found that although coronary blood flow did not increase with nitrites, arterial pressure decreased, resulting in a decline in calculated coronary resistance in patients with coronary artery disease.

Since anesthesia can radically alter neural control of the circulation $(28,31)$, it is understandable that many of the previous studies did not note a reflex increase in contractility following the hypotensive effects of i.v. nitroglycerin $(5,7,15,17)$. Some studies even failed to find substantial increases in heart rate $(14,16)$. Since both of these effects stimulate myocardial metabolism, and thereby augment coronary blood flow (45-47) it follows that nitroglycerin administered to anesthetized preparations with an open chest, does not elicit a secondary rise in coronary blood flow and reduction in coronary resistance $(8-10,14)$.

In the healthy conscious dog, in which the effects of anesthesia are absent and all control mechanisms are intact, i.v. nitroglycerin elicited large reflex increases in heart rate (100 beats $/ \mathrm{min}$ ) and a modest reflex increase in the myocardial contractile state $(\mathrm{dP} / \mathrm{dt}) / \mathrm{P}$ rose by $22 \%$ ). Both of these effects were much less when nitroglycerin was administered sublingually and in fact the small increases in velocity and $(\mathrm{dPdt}) / \mathrm{P}$ were not observed when heart rate was maintained constant by atrial stimulation (Fig. 7). Similarly, the reflex effects on contractility after i.v. administration were slightly but significantly less when heart rate was not allowed to rise (Fig. 7). This could not be explained on the basis that simple tachycardia increased contractility, since the control level of velocity and $(\mathrm{dP} / \mathrm{dt}) / \mathrm{P}$ were actually less at the higher rate. Moreover, we have recently observed that elevating heart rate at rest in conscious dogs with atrial pacing does not increase myocardial contractility (48). It may be that cardiac receptors are partially responsible for the afferent arc of the reflex inotropic effects $(49,50)$; a reduction in cardiac size stimulating a reflex increase in contractility. When heart rate was allowed to vary, nitroglycerin reduced ventricular size substantially, but when heart rate was maintained constant, the effects on ventricular size were substantially less. Thus, a reflex increase in contractility induced by a decrease in cardiac size would be considerably attenuated by maintaining heart rate constant. It is important to note that a negative inotropic effect was not observed, when the drug was administered either intravenously or sublingually, since some groups have proposed a negative inotropic effect of the drug, either direct $(5,7,16,17)$ or due to an adrenergic blocking effect $(15,18)$.

Although it is recognized that nitroglycerin causes ventricular size to diminish $(19,20,25,26,51,52)$ it is not generally appreciated that the reduction in size is due predominantly to the associated tachycárdia. A1though this effect was observed when the drug was given intravenously it was even more apparent after sublingual administration (Fig. 7).

In conclusion, the present investigation demonstrates a number of important features not generally appreciated of the action of nitroglycerin on the normal heart and coronary vessels. I.v. nitroglycerin in the conscious dog produces two phases of coronary dilatation; the first phase is due to a direct effect on the coronary vessels while the later phase is associated with changes in cardiac size, rate, and contractility. A negative inotropic effect was not observed, but a reflex increase in contractility occurred. At a constant heart rate, the decreases in ventricular dimensions are substantially diminished and the reflex increase in contractility is reduced. Sublingual nitroglycerin produces directionally similar but quantitatively lesser and more prolonged effects than i.v. nitroglycerin, and at a constant heart rate, the reduction in left ventricular end diastolic size was less. no effect on contractility was observed, but coronary flow still increased slightly and distinct reduction in coronary resistance occurred.

\section{ACKNOWLEDGMENTS}

We are grateful for technical assistance from D. P. McKown, D. Hendrick, and F. Werner, and for assistance in preparing the manuscript from $\mathrm{K}$. Bateman. We appreciate 
the generous supply of propranolol from Ayerst Co. We also thank Dr. Eugene Braunwald for encouragement and advice.

This work was supported in part by U. S. Public Health Service Grants HE 12373, HE 13441, and HL 15631-01.

\section{REFERENCES}

1. Boyer, N. H., and H. D. Green. 1941. The effects of nitrites and xanthines on coronary inflow and blood pressure in anesthetized dogs. Am. Heart J. 21: 199.

2. Eckstein, R. W., W. B. Newberry, J. A. McEachen, and G. Smith. 1951. Studies of the antiadrenergic effects of nitroglycerin on the dog heart. Circulation. 4: 534.

3. Malindzak, G. S., Jr., H. D. Green, and P. L. Stagg. 1970. Effects of nitroglycerin on flow after partial constriction of the coronary artery. J. Appl. Physiol. 29: 17.

4. Eckenhoff, J. E., and J. H. Hafkensciel. 1947. The effect of nikethamide on coronary blood flow and cardiac oxygen metabolism. J. Pharmacol. Exp. Ther. 91: 362.

5. Bergamaschi, M., and A. H. Glässer. 1963. Effect of the endecapeptide eledoisin on the coronary blood flow: comparison with nitroglycerin, bardykinin, and epinephrine in the dog. Circ. Res. 13: 329.

6. Marchetti, G. V., L. Merlo, and R. M. Antognetti. 1964. The effects of nitroglycerin on the coronary blood flow and oxygen consumption of the myocardium in anesthetized dogs. Am. J. Cardiol. 13: 51 .

7. Aviado, D. M., L. E. Folle, and S. Bellet. 1968. Cardiopulmonary effects of glyceryl trinitrate and isosorbide dinitrate. Cardiologia. 52: 287.

8. Vyden, J. K., M. Carvalho, E. Boszormenyi, T.-W. Lang, H. Bernstein, and E. Corday. 1970. Effect of glyceryl trinitrate (nitroglycerin) on the systemic and coronary circulation of the dog. Am. J. Cardiol. 25: 53.

9. Gillis, R. A., and K. I. Melville. 1971. Effects of sublingually and intravenously administered nitroglycerin on the cardiovascular system of the dog. Am. J. Cardiol. 28: 38 .

10. Mathes, P., and J. Rival. 1971. Effect of nitroglycerin on total and regional coronary blood flow in the normal and ischaemic canine myocardium. Cardiovasc. Res. $5: 54$.

11. Fam, W. M., and M. McGregor. 1968. Effect of nitroglycerin and dipyridamole on regional coronary resistance. Circ. Res. 22: 649.

12. Winbury, M. M., B. B. Howe, and H. R. Weiss. 1971. Effect of nitroglycerin and dipyridamole on epicardial and endocardial oxygen tension-further evidence for redistribution of myocardial blood flow. J. Pharmacol. Exp. Ther. 176: 184.

13. Winbury, M. M. 1971. Redistribution of left ventricular blood flow produced by nitroglycerin. An example of integration of the macro- and microcirculation. Circ. Res. 28(Suppl. 1) : 140.

14. Ross, G., and C. Jorgensen. 1968. Effects of iproveratril and nitroglycerin in the heart and coronary circulation of dogs. Am. Heart J. 76: 74.

15. Gillis, R. A., and K. I. Melville. 1970. Coronary flow changes and cardiac adrenergic blockade during nitroglycerin infusions. Eur. J. Pharmacol. 13: 15.

16. Darby, T. D., J. H. Sprouse, and R. P. Walton. 1958. Evaluation of sympathetic reflex effects on the inotropic action of nitroglycerin, quinidine, papaverine, aminophylline, and isoproterenol. J. Pharmacol. Exp. Ther. 122: 386 .
17. Darby, T. D., and E. E. Aldinger. 1960. Further studies of the effects on myocardial energy utilization elicited by nitroglycerine. Circ. Res. 8: 100 .

18. Raab, W., and E. Lepeschkin. 1950. Anti-adrenergic effects of nitroglycerin on the heart. Circulation. 1: 733.

19. Gordon, B., and G. Wells. 1924. The effect of amyl nitrite, bleeding and epinephrine on the blood pressure and the size of the cat's heart. Arch. Intern. Med. 33: 738.

20. Beck, C. S., and E. Holman. 1925. The physiological response of the circulatory system to experimental alterations. II. The effect of variations in total blood volume. J. Exp. Med. 42: 681 .

21. Bernstein, L., G. C. Friesinger, P. R. Lichtlen, and R. S. Ross. 1966. The effect of nitroglycerin on the systemic and coronary circulation in man and dogs. Myocardial blood flow measured with xenon-133. Circulation. 33: 107.

22. Brachfeld, N., J. Bozer, and R. Gorlin. 1959. Action of nitroglycerin on the coronary circulation in normal and in mild cardiac subjects. Circulation. 19: 697.

23. Luebs, E.-D., A. Cohen, E. J. Zaleski, and R. J. Bing. 1966. Effect of nitroglycerin, intensain, isoptin and papaverine on coronary blood flow in man. Measured by the coincidence counting technic and Rubidium-84. Am. J. Cardiol. 17: 535 .

24. Bing, R. J., A. Bennish, G. Bluemchen, A. Cohen, J. P. Gallagher, and E. J. Zaleski. 1964. The determination of coronary flow equivalent with coincidence counting technic. Circulation. 29: 833.

25. Williams, J. F., G. Glick, and E. Braunwald. 1965. Studies on cardiac dimensions in intact unanesthetized man. V. Effects of nitroglycerin. Circulation. 32: 767.

26. Brandt, J. L., A. Caccese, and W. Dock. 1952. Slitkymographic evidence that nitroglycerin decreases heart volume and stroke volume, while increasing the amplitude of ballistocardiographic waves. Am. J. Med. 12: 650 .

27. Gregg, D. E., E. M. Khouri, and C. R. Rayford. 1965. Systemic and coronary energetics in the resting unanesthetized dog. Circ. Res. 16: 102.

28. Vatner, S. F., D. Franklin, and E. Braunwald. 1971. Effects of anesthesia and sleep on circulatory response to carotid sinus nerve stimulation. Am. J. Physiol. 220: 1249.

29. Vatner, S. F., C. B. Higgins, D. Franklin, and E. Braunwald. 1971. Effects of a digitalis glycoside on coronary and systemic dynamics in conscious dogs. Circ. Res. 28: 470.

30. Vatner, S. F., C. B. Higgins, T. Patrick, D. Franklin, and E. Braunwald. 1971. Effects of cardiac depression and of anesthesia on the myocardial action of a cardiac glycoside. J. Clin. Invest. 50: 2585.

31. Vatner, S. F., C. B. Higgins, D. Franklin, and E. Braunwald. 1972. Extent of carotid sinus control of the myocardial contractile state in conscious dogs. J. Clin. Invest. 51: 995.

32. Van Citters, R. L., and D. L. Franklin. 1966. Telemetry of blood pressure in free-ranging animals via an intravascular gauge. J. Appl. Physiol. 21: 1633.

33. Franklin, D. E., N. W. Watson, K. E. Pierson, and R. L. Van Citters. 1966. Technique for radio telemetry of blood-flow velocity from unrestrained animals. $A m$. J. Med. Electron. 5: 24.

34. Vatner, S. F., D. Franklin, and R. L. Van Citters. 1970. Simultaneous comparison and calibration of the Doppler and electromagnetic flowmeters. J. Appl. Physiol. 29: 907. 
35. Rushmer, R. F., D. L. Franklin, and R. M. Ellis. 1956. Left ventricular dimensions recorded by sonocardiometry. Circ. Res. 4: 684.

36. Stegall, H. F., M. B. Kardon, H. L. Stone, and V. S. Bishop. 1967. A portable, simple sonomicrometer. J. Appl. Physiol. 23: 289.

37. Snedecor, G. W., and W. G. Cochran. 1967. Statistical Methods. The Iowa State University Press, Ames. 6th edition.

38. Glick, G., E. H. Sonnenblick, and E. Braunwald. 1965. Myocardial force-velocity relations studied in intact unanesthetized man. J. Clin. Invest. 44: 978.

39. Mason, D. T., E. Braunwald, J. W. Covell, E. H. Sonnenblick, and J. Ross, Jr. 1971. Assessment of cardiac contractility. The relation between the rate of pressure rise and ventricular pressure during isovolumic systole. Circulation. 44 : 47.

40. Wolk, M. J., J. F. Keefe, O. H. L. Bing, L. J. Finkelstein, and $H$. J. Levine. 1971. Estimation of $V_{\max }$ in auxotonic systoles from the rate of relative increase of isovolumic pressure: $(\mathrm{dP} / \mathrm{dt}) \mathrm{kP}$. J. Clin. Invest. 50: 1276.

41. Parker, J. O., R. O. West, and S. Di Giorgi. 1971. The effect of nitroglycerin on coronary blood flow and the hemodynamic response to exercise in coronary artery disease. Am. J. Cardiol. 27: 59.

42. Cohen, A., J. P. Gallagher, E.-D. Luebs, Z. Varga, J. Yamanaka, E. J. Zaleski, G. Bluemchen, and R. J. Bing. 1965. The quantitative determination of coronary flow with a positron emitter (Rubidium-84). Circulation. 32: 636.
43. Rowe, G. G., C. J. Chelius, S. Afonso, H. P. Gurtner, and C. W. Crumpton. 1961. Systemic and coronary hemodynamic effects of erythrol tetranitrate. J. Clin. Invest. 40: 1217.

44. Hollander, W., I. M. Madoff, and A. V. Chobanian. 1963. Local myocardial blood flow as indicated by the disappearance of $\mathrm{NaI}^{181}$ from the heart muscle: studies at rest, during exercise and following nitrite administration. J. Pharmacol. Exp. Ther. 139: 53.

45. Berne, R. M. 1964. Regulation of coronary blood flow. Physiol. Rev. 44: 1.

46. Braunwald, E. 1971. Control of myocardial oxygen consumption. Physiological and clinical considerations. $\mathrm{Am}$. J. Cardiol. 27: 416.

47. Gregg, D. E., and L. C. Fischer. 1963. Blood supply to the heart. Handb. Physiol. 2: 1517.

48. Higgins, C. B., S. F. Vatner, R. W. Millard, D. Franklin, and E. Braunwald. 1972. Effect of tachycardia on left ventricular (LV) contractility in conscious dogs. Clin. Res. 20: 206. (Abstr.)

49. Hakumäki, M. O. K. 1970. Function of the left atrial receptors. Acta Physiol. Scand. Suppl. 344: 1.

50. Korner, P. I. 1971. Integrative neural cardiovascular control. Physiol. Rev. 51: 312.

51. Frick, M. H., R. Balcon, D. Cross, and E. Sowton. 1968. Hemodynamic effects of nitroglycerin in patients with angina pectoris studied by an atrial pacing method. Circulation. 37: 160

52. O'Rourke, R. A., V. S. Bishop, P. A. Kot, and J. P. Fernandez. 1971. Hemodynamic effects of nitroglycerin and amyl nitrite in the conscious dog. J. Pharmacol. Exp. Ther. 177: 426. 